\title{
Family docs: the power of numbers
}

A dvancing the concept of patient-centred care, encouraging greater collaboration with other health organizations and government, and effectively utilizing the collective influence of primary care practitioners, researchers and educators are among the top priorities of the new president of the College of Family Physicians of Canada (CFPC).

"I believe they are vital to the success of all our initiatives," Dr. MarieDominique Beaulieu said Nov. 16 after officially accepting the presidency at the Family Medicine Forum in Toronto, Ontario.

Beaulieu, a professor of family medicine at the University of Montréal in Quebec, practises comprehensive family medicine at the Family Medicine Group of Hôpital Notre-Dame du Centre hospitalier de l'Université de Montréal. She grew up in Québec City, was educated and trained in medicine at Laval University in Québec City and has a special interest in primary care research.

It would be fair to say that promoting patient-centred care will be a personal priority over the coming year at the helm of the college, said Beaulieu. It is not a new concept but is enjoying a second wind, she suggested, and has room to evolve in directions such as forming new partnerships with patients and their families. "Being patient-centred is not only a matter of seeing the disease through the patient's eyes. It is really seeing his or her entire health care experience."

Another important issue within family medicine is ensuring that the efforts of clinicians, educators and researchers are fully realized, said Beaulieu. "I am convinced that innovation can only arrive from the synergy of these three major types of expertise."

But better collaboration within elements of the medical community is not enough, suggested Beaulieu. The college must also strive to build more relationships with governments and with other health organizations. "We talk a lot about interprofessional collaboration, but I think we also have to think about interorganizational collaboration. No organization can cause effective change single-handedly."

Prior to Beaulieu's inauguration, outgoing president Dr. Sandy Buchman delivered his "state of the college" address to the forum, which is cohosted by the CFPC, the Ontario College of Family Physicians and the CFPC's Sections of Teachers and Researchers.

Buchman sketched the college's endeavours to advance the concept of the patient's medical home, a model of care in which the family physician or team is essentially a hub for all of a patient's medical needs, including wellness, preventive care, the management of chronic diseases and coordination with specialists.

"We know it's sustainable, and you get the best value for your health care dollar," he said.

The college has also honed its position on family physicians with special interests and focused practices, the intent being to support both broad practices and those narrower in scope, Buchman indicated. This has included awarding certificates of added competence in areas such as emergency medicine and palliative care, while developing the criteria required to bring other focused interests into the fold.

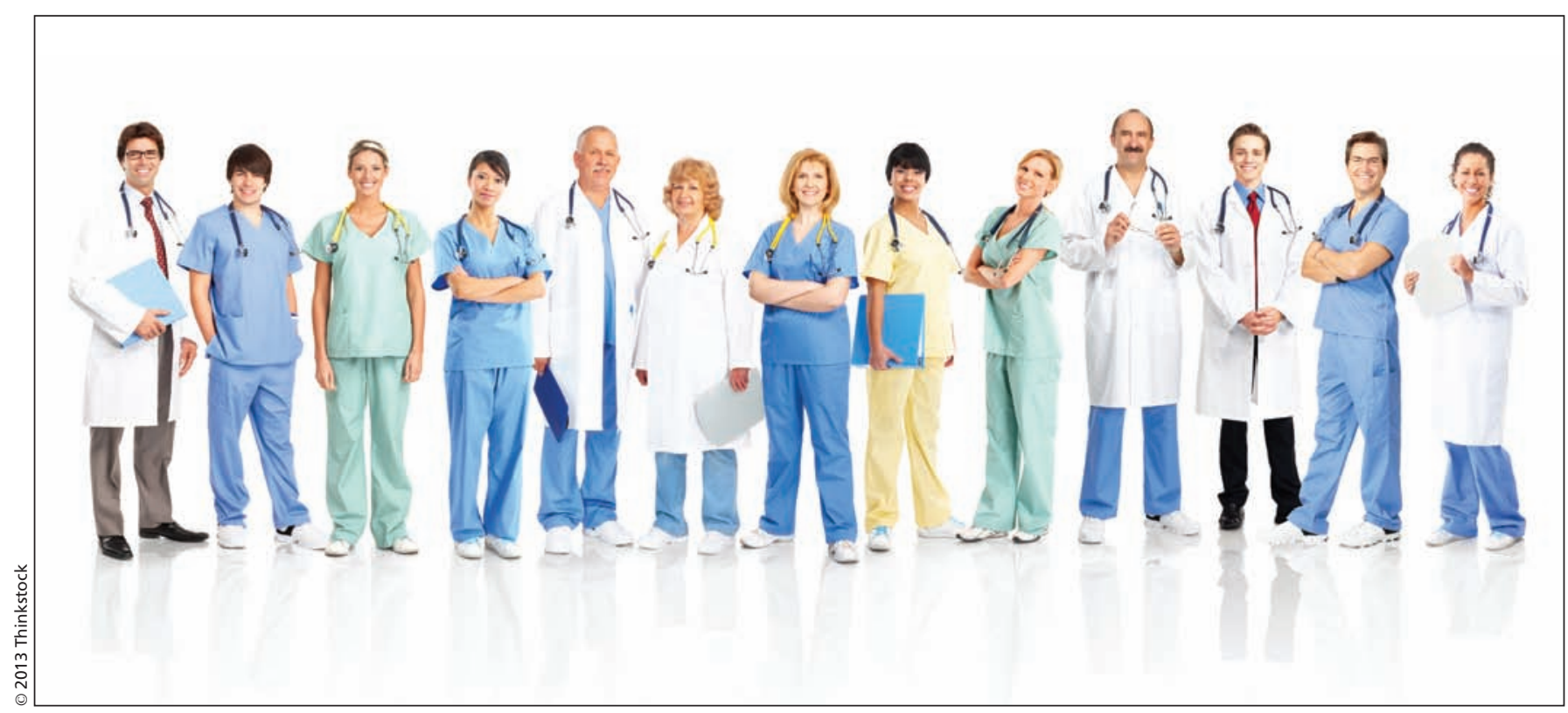

The diversity of expertise within the community of Canada's family doctors should help to forge new partnerships, with both patients and policy-makers, says College of Family Physicians of Canada President Dr. Marie-Dominique Beaulieu. 
"The real challenges are to determine what are the core competencies for a family medicine graduate and what would be the enhanced or added competencies beyond that," Buchman said.

Other areas the college continues to explore include enhancing the degree of family medicine research, pushing forward with its "Triple-C" competency- based curriculum for medical education (i.e., comprehensive, continuity of education and patient care, and centred in family medicine) and exploring its relationship with the pharmaceutical industry. "It's really looking at organizational conflict of interest. It's about our credibility and the trust in our organization by our members and by the public," Buchman said.
Buchman also noted that family practice appears an increasingly attractive path. In 2003 , only $24 \%$ of graduating medical students made primary care their career choice but "now we are up to $35 \%$ and we feel we are going to reach $40 \%$, our target, some time soon." - Roger Collier, CMAJ

CMAJ 2013. DOI:10.1503/cmaj.109-4355 